\title{
Decreased Concomitant Drug Half Life
}

National Cancer Institute

\section{Source}

National Cancer Institute. Decreased Concomitant Drug Half Life. NCI Thesaurus. Code C54616.

Decreased period of time required for the concentration or amount of a concomitant drug in the body to be reduced to exactly one-half of a given concentration or amount. 